\title{
ESTUDO DO RISCO DE CONTAMINAÇÃO DOS AQUÍFEROS NA ÁREA DO CENTRO INDUSTRIAL DO SUBAÉ-FEIRA DE SANTANA-BA: CARACTERIZAÇÃO GEOTÉCNICA E HIDRÁULICA DO SOLO.
}

\author{
Gustavo Lucas Oliveira Goncalves ${ }^{1}$; Riseuda Pereira de Sousa ${ }^{2}$; \\ 1. Bolsista FAPESB, Graduando em Engenharia Civil, Universidade Estadual de Feira de Santana, e-mail: \\ gustavo lucas02@hotmail.com \\ 2. Orientadora, Departamento de Tecnologia, Universidade Estadual de Feira de Santana, e-mail: \\ riseuda.sousa@gmail.com
}

\begin{abstract}
PALAVRAS-CHAVE: Ascensão capilar, condutividade hidráulica e curva de retenção de umidade.
\end{abstract}

\section{INTRODUÇÃO}

A contaminação do solo e a perda da qualidade da água resultantes do desenvolvimento das atividades econômicas constituem graves problemas ambientais, podendo afetar a qualidade de vida de todos, sendo por isso, objeto de diversos estudos, nos quais a física do solo tem contribuição efetiva na solução de problemas relacionados com estes aspectos.

De acordo com Presa (1998), qualquer alteração nas condições ambientais circundantes do solo, provoca desequilíbrio físico-químico, que pode desencadear processos e reações em busca de um equilíbrio. Portanto, assim como presença de um contaminante, através de fenômenos físicos, químicos e biológicos, altera as características e propriedades do solo; o comportamento do fluxo, que pode ser plenamente vertical ou conter certo percentual de espalhamento vertical, depende das características do meio percolante como: tipo de solo e sua mineralogia; capacidade de troca catiônica (CTC); espécies de cátions adsorvidos; velocidade de percolação; teor de matéria orgânica; condições hidrogeológicos, temperatura e $\mathrm{pH}$ do meio; propriedades do fluido como: viscosidade, massa específica e tensão superficial e consequentemente das relações (P-K) (permeabilidade) e P-S(curva de retenção de água). (COSTA, 2002; Oliveira, 1995; Sousa, 2012)

Assim, utilizado água como fluido percolante, este trabalho visa estudar o solo da região do Centro Industrial de Subaé realizando a caracterização física, química, mineralógica e hidráulica deste solo aplicado metodologias já conhecidas na literatura.

\section{MATERIAL E MÉTODOS OU METODOLOGIA (ou equivalente)}

A caracterização física do material foi composta por: peso especifico dos grãos, granulometria conjunta, compactação, limite de liquidez e limite de plasticidade. Todas foram realizadas seguindo suas respectivas normas e realizadas no laboratório de Mecânica dos Solos da Universidade Estadual de Feira de Santana (UEFS).

A caracterização química envolveu análises de natureza qualitativa e quantitativa, que permitiram a identificação das espécies químicas presentes no solo e o teor relativo a cada uma, por meio da fluorescência de raios- X. O ensaio foi realizado no Laboratório de Geotecnia Ambiental da UFBA (GEOAMB - UFBA). Para este ensaio, amostras, com cerca de 30 gramas do solo passado na peneira 4 e secas à $100^{\circ} \mathrm{C}$ por 24 horas, foram submetidas ao analisador de Fluorescência de Raio X portátil (X-MET 7500, Oxford Instruments, USA), empregando-se o método de análise Soil LE FP, por 15 segundos. Os resultados são mostrados na Tabela $X$.

A caracterização mineralógica foi realizada no Laboratório de Ensaios em Durabilidade dos Materiais (LEDma) da Universidade Federal da Bahia (UFBA), submetendo o solo, passadas na peneira $\# 200$ e seco à $100^{\circ} \mathrm{C}$ por $24 \mathrm{~h}$, a um difratômetro de raio-X, (D2 Phaser, Bruker, USA) com tubo de cobre $(\lambda=1,5418 \mathrm{~A})$, velocidade de $2 \% \mathrm{~min}$, rotação de $15 \%$ min, potência de $30 \mathrm{KV}$ e corrente de $10 \mathrm{~mA}$. 
O teor de sólidos voláteis ou matéria orgânica presente foi realizada levando-se o solo, seco em estufa a $60^{\circ} \mathrm{C}$ por 24 horas, ao forno mulfla para calcinação a uma temperatura de aproximadamente $600^{\circ} \mathrm{C}$ por duas horas.

Para a caracterização hidráulica que envolveu os ensaios de: ascensão capilar, permeabilidade e curva de retenção de umidade (CRU), foram utilizados os métodos descritos a seguir.

A ascensão capilar foi executada em colunas PET com $2 \mathrm{~m}$ de altura, utilizado o solo passado na peneira de $4 \mathrm{~mm}$, nas condições de umidade higroscópica, e compactado com densidade nas condições de campo, utilizando a técnica de Sousa, 2012 e Oliveira, 1995.

O ensaio de permeabilidade foi realizado seguindo a Norma NBR 13292 utilizando permeâmetro de parede rígida de carga variável, existente no laboratório de Mecânica dos solos da UEFS e o solo compactado nas condições de Proctor normal.

Para a montagem da CRU do solo, ramo de umedecimento, foram empregados dois métodos: um, para a faixa de sucção 0 a $20 \mathrm{kPa}$, utilizou-se a umidade gravimétrica, de amostras do solo, coletado, ao término do ensaio de ascensão capilar, a diferentes alturas da coluna 1, empregando anéis de PVC. O segundo trabalhando com os dados de sucção acima de $20 \mathrm{kPa}$ utilizou-se o psicrômetro modelo WP4C-Water Potential Meter (Decagon Devices, Pullman, WA) pertencente ao Laboratório de Geotecnia Ambiental da Universidade Federal da Bahia (GEOAMB - UFBA).

O fluído utilizado nos ensaios (água da torneira) foi submetido à ensaios utilizando equipamentos da UEFS. No laboratório de Mecânica dos Fluidos foram feitos os ensaios de: viscosidade, utilizando um viscosímetro de Cannon-Fenskee, peso específico e massa específica por picnômetria. No Laboratório de Saneamento foi feita a determinação do pH.

\section{RESULTADOS E/OU DISCUSSÃO (ou Análise e discussão dos resultados)}

Os ensaios granulométricos mostraram que o solo do CIS é uma areia argilosa de alta plasticidade $(\mathrm{IP}=21 \%)$, que traz na sua composição pedregulho $(3,6 \%)$, areia grossa $(9,9 \%)$, areia média $(21,5)$, areia fina $(17 \%)$, silte $(4,5 \%)$ e argila $(43,5 \%)$.

A análise química (Tabela 1), mostrando que o solo apresenta maiores teores de Sílica $(63,78 \%)$ e Alumínio $(32,7)$, o que, com na análise mineralógica por difração de Raio-X revelou a presença dos argilominerais quartzo, haloisita e caulinita.

\begin{tabular}{|l|l|l|l|l|l|l|l|l|l|l|}
\hline Mineral & $\mathrm{Si}$ & $\mathrm{Al}$ & $\mathrm{Cl}$ & $\mathrm{Ti}$ & $\mathrm{Fe}$ & $\mathrm{Co}$ & $\mathrm{Ca}$ & $\mathrm{Mo}$ & $\mathrm{Ag}$ & $\mathrm{Se}$ \\
\hline Teor $(\%)$ & 63,772 & 32,702 & 3,150 & 0,179 & 0,109 & 0,049 & 0,024 & 0,005 & 0,006 & 0,001 \\
\hline
\end{tabular}

Tabela 1: Caracterização química por FRX

Também foi constatada que o solo dispõe de um baixo teor de matéria orgânica, da ordem $5,77 \%$, ao se realizar o ensaio de STV.

Esta composição do solo conduziu a um ensaio de permeabilidade por carga variável, que levou a obtenção da condutividade hidráulica saturada de $5,13714 \mathrm{E}-06 \mathrm{~cm} / \mathrm{s}$.

Os ensaios de ascensão capilar (Figuras 1) realizados nas três colunas do solo areno argiloso do CIS, no estado compactado, cuja densidade atingida foi de $1,66 \mathrm{~g} / \mathrm{cm}^{3}$, mostram que as curvas obtidas (Figuras 2 e 3), diferente das areias e de outros solos argilosos, que são ajustadas com os modelos de Green e Ampt (1911) e de Philip (1969), possivelmente devido a irregularidade dos poros, apresenta um comportamento de ascensão típico do modelo de Kostiacov (1932), conforme parâmetros de ajuste vistos na Tabela (2),

\begin{tabular}{|c|c|c|c|c|}
\hline \multirow{2}{*}{ Modelo } & \multirow{2}{*}{ Coluna } & \multicolumn{2}{|c|}{ Parâmetro de ajuste } & \multirow{2}{*}{$\begin{array}{c}\text { Coeficiente de } \\
\text { correlação }\left(\mathrm{R}^{2}\right)\end{array}$} \\
\cline { 2 - 5 } & & $\mathrm{a}$ & $\mathrm{b}$ & 0,99 \\
\hline \multirow{3}{*}{$H=a \cdot t^{b}$} & 1 & 1,7821 & 0,2722 & 0,99 \\
\cline { 2 - 5 } & 2 & 1,8130 & 0,2722 & 0,99 \\
\cline { 2 - 5 } & 3 & 1,7500 & 0,2723 & 0,99 \\
\cline { 2 - 5 } & Média & 1,7817 & 0,2722 & \\
\hline
\end{tabular}

Tabela 2-Parâmetros de ajustes 


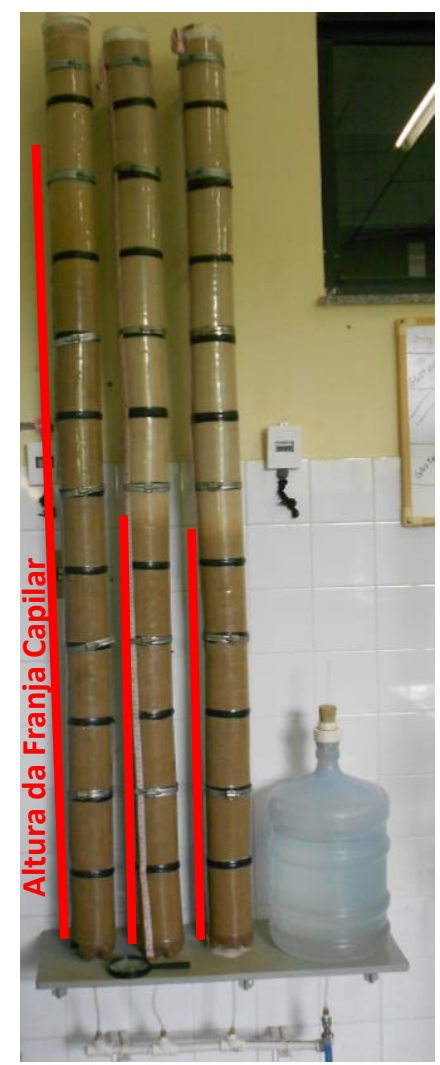

Figura 1- Ascensão capilar nas colunas 1, 2 e 3

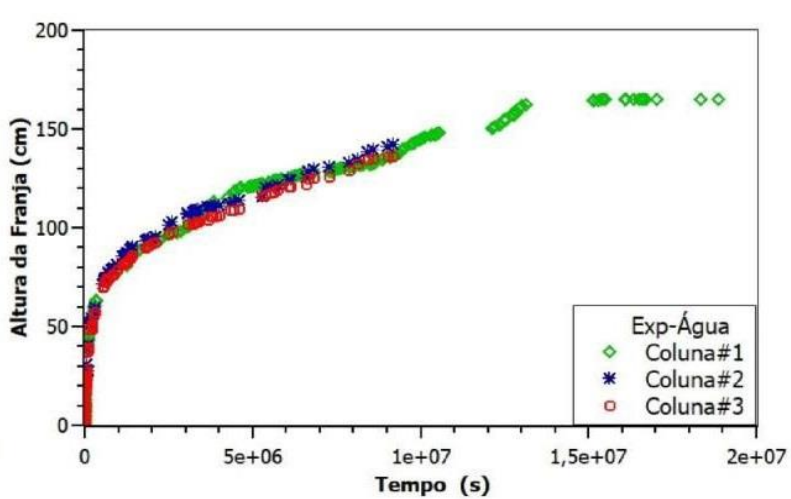

Figura 2- Curvas de ascensão capilar das colunas 1, 2 e 3

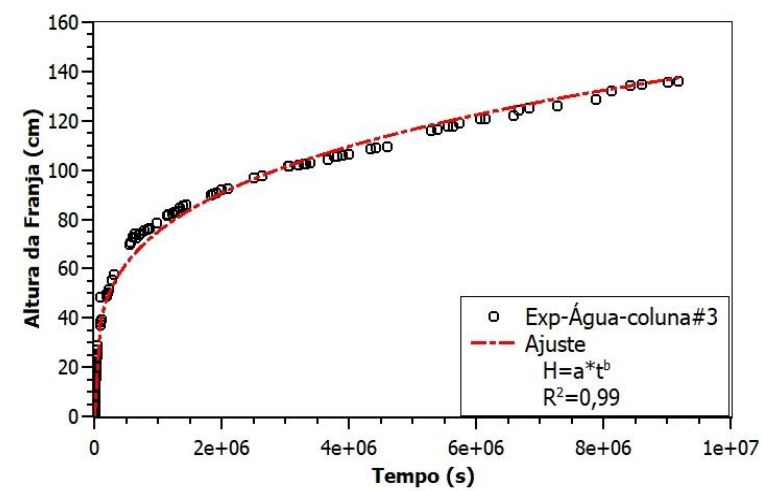

Figura 3- Ajuste das curvas de ascensão capilar das colunas 3

A Figura 3 mostra a curva de retenção de umidade a água obtida no ensaio realizado com o psicrômetro modelo WP4C-Water Potential Meter, para a amostra de solo no estado indeformado, enquanto a Tabela 5 apresenta os parâmetros obtidos para o ajuste realizado com um modelo bimodal desenvolvido e proposta por Carducci et al (2011), a partir do modelo de van Genuchten (1980), e por isto é denominado de Duplo VG.

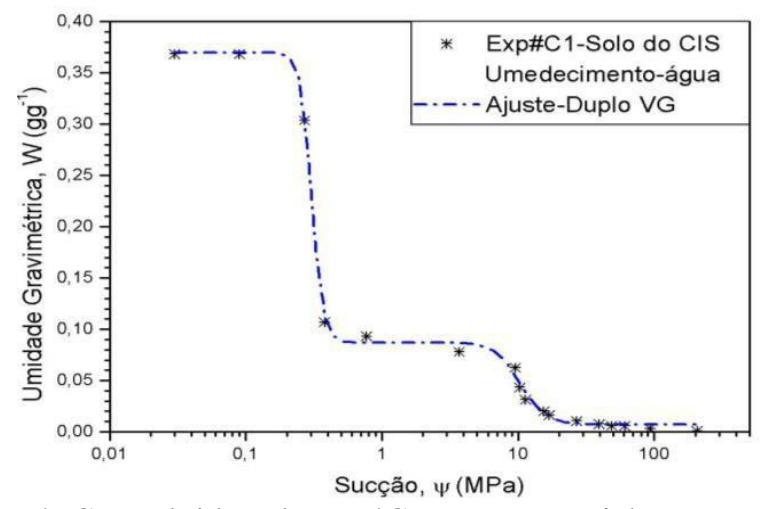

Figura 4- CRU obtida pelo WP4C-Water Potential Meter

\begin{tabular}{|c|c|c|c|c|c|c|c|c|c|c|}
\hline $\operatorname{Exp}$ & $\begin{array}{c}\alpha_{\text {etx }} \\
\mathrm{kPa}^{-1}\end{array}$ & $\mathrm{n}_{\mathrm{etx}}$ & $\mathrm{m}_{\mathrm{etx}}$ & $\begin{array}{c}\alpha_{\text {est }} \mathrm{kPa}^{-} \\
1\end{array}$ & $\mathrm{n}_{\text {est }}$ & $\mathrm{m}_{\text {est }}$ & $\begin{array}{c}\mathrm{W}_{\text {res }} \\
(\%)\end{array}$ & $\begin{array}{c}\mathrm{w}_{\text {pmp }} \\
(\%)\end{array}$ & $\begin{array}{c}\mathrm{w}_{\text {sat }} \\
(\%)\end{array}$ & $\mathrm{R}^{2}$ \\
\hline \#C1 & 0,1027 & 5,1207 & 0,8047 & 3,3281 & 10,7908 & 0,9073 & 0,70 & 8,7 & 37,0 & 0,99 \\
\hline
\end{tabular}

Tabela 5- Parâmetros de ajuste da curva de retenção à água

Como pode ser visto na curva da figura 4 , a ação da fração arenosa do solo, atuando no transporte da água, conduz a um acentuado decréscimo de umidade após o valor de entrada de ar. De acordo com a distribuição dos pontos e o ajuste a curva apresentou formato bimodal, característico de solos com distribuição irregular de poros, onde o 
patamar horizontal da curva de retenção é indicativo da ausência de poros para aquele intervalo de sucção.

\section{CONSIDERAÇÕES FINAIS (ou Conclusão)}

Com a realização dos ensaios de caracterizações: Físicas, Química, Mineralógica e Hidráulica (curva de retenção de água, condutividade hidráulica e curva de ascensão capilar) chegou-se as seguintes conclusões:

O solo da região do Centro Industrial do Subaé, CIA (Lat. 12¹7’27,5”S e Long $\left.38^{\circ} 57^{\prime} 49^{\prime \prime} \mathrm{W}\right)$ é uma areia argilosa de alta plasticidade (21\%), que traz na sua composição física, pedregulho $(3,6 \%)$, areia grossa $(9,9 \%)$, areia média $(21,5)$, areia fina $(17 \%)$, silte $(4,5 \%)$ e argila $(43,5 \%)$

A constatação da existência no solo dos argilominerais quartzo, haloisita e caulinita diante da presença de alto teores de Sílica $(63,78 \%)$ e Alumínio $(32,7)$;

A característica argilosa do solo conduziu a realização do ensaio de condutividade hidráulica por carga variável com obtenção de ksat de 5,13714E-06 cm/s;

O modelo empírico que melhor se adequou aos dados experimentais de ascensão capilar foi o de Kostiacov (1932), diferente das areias e de outros solos argilosos, que são ajustadas com os modelos de Green e Ampt (1911) e de Philip (1969), possivelmente devido a irregularidade dos poros;

O solo no estado indeformado conduz a obtenção de uma curva retenção de água de modelo bimodal, comportamento típico de solos com distribuição irregular de poros, que possibilita ajuste com modelo de duplo van Genuchten (1980).

\section{REFERÊNCIAS}

CARDUCCI, C.E.; OLIVEIRA, G.C.; SEVERIANO, E.C.; ZEVIANI, W.M.; Modelagem da curva de retenção de água de latossolos utilizando a equação duplo van genuchten. $R$. Bras. Ci. Solo, 35:7786, 2011.

COSTA, P. O. S. Avaliação em laboratório do transporte de contaminantes no solo do Aterro Sanitário de Sauipe/BA.2002.188 f. Dissertação (Mestrado em Engenharia Civil: Geotecnia) -Departamento de Engenharia Civil Pontifícia, Universidade Católica do Rio de Janeiro, Rio de Janeiro.

GREEN, W. H.; AMPT, G. A. Studies on soil physics, 1. The theory of air and water through soils. J. Agr. Sci. v. 4, 1-24, 1911.

KOSTIACOV, A. N. On the dynamics of the coefficient of water percolation in soils and on the necessity it from a dynamic point of view for purposes of amelioration. In Transactions, 6th committee Inter. Soc Soil. Sci. Moscow. Part A 17-21, 1932.

OLIVEIRA, I. B. (1995). Infiltration of organic liquids in unsaturated sands: comparison of experimental measurements with scaled and unscaled analytical solutions. 335f. Tese (Doctor Philosophy in Environmental Engineering), Universidad of Michigan. Ann Arbor, Michigan, USA.

PHILIP, J. R. (1969). Theory of infiltration. In: Advances in Hydroscience. Elsevier.V.5, p. 215-296

PRESA, E. P.. Geotecnia Ambiental: Meios não saturados e sucção nos solos características e comportamento da água do solo. Salvador, 1998. 51 p.

SOUSA, R. P; Estudos dos fluxos de óleo diesel e água em solos não saturados: desenvolvimento experimental e modelagem matemática. Tese de doutorado apresentada ao Programa de Pós-Graduação em Engenharia Industrial da Universidade Federal da Bahia. 2012.

VAN GENUCHTEN, M. TH. A closed-form equation for predicting the hydraulic conductivity of unsaturated soils. Soil Sci. Soc. Am. J., n. 44, p. 892-898, 1980. 